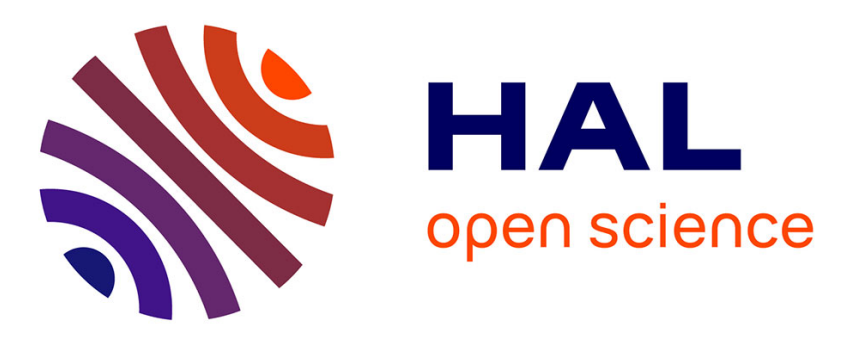

\title{
(19th ICPR) Production planning by pinch analysis for biomass use in dynamic and seasonal markets
}

\author{
Jens Ludwig, Martin Treitz, O Rentz, Jutta Geldermann
}

\section{To cite this version:}

Jens Ludwig, Martin Treitz, O Rentz, Jutta Geldermann. (19th ICPR) Production planning by pinch analysis for biomass use in dynamic and seasonal markets. International Journal of Production Research, 2009, 47 (08), pp.2079-2090. 10.1080/00207540802392577 . hal-00513047

\section{HAL Id: hal-00513047 \\ https://hal.science/hal-00513047}

Submitted on 1 Sep 2010

HAL is a multi-disciplinary open access archive for the deposit and dissemination of scientific research documents, whether they are published or not. The documents may come from teaching and research institutions in France or abroad, or from public or private research centers.
L'archive ouverte pluridisciplinaire HAL, est destinée au dépôt et à la diffusion de documents scientifiques de niveau recherche, publiés ou non, émanant des établissements d'enseignement et de recherche français ou étrangers, des laboratoires publics ou privés. 


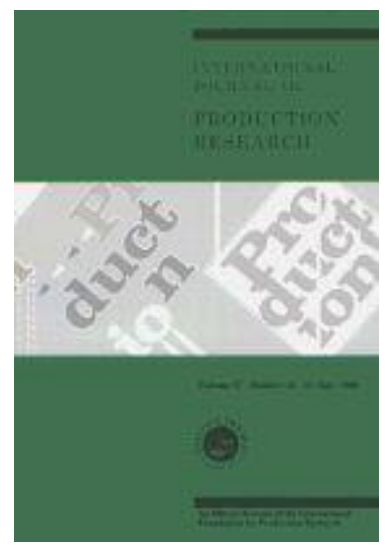

(19th ICPR) Production planning by pinch analysis for biomass use in dynamic and seasonal markets

\begin{tabular}{|r|l|}
\hline Journal: & International Journal of Production Research \\
\hline Manuscript ID: & TPRS-2008-IJPR-0113.R1 \\
\hline Manuscript Type: & Original Manuscript \\
\hline Author: & 24-Jul-2008 \\
\hline Complete List of Authors: & $\begin{array}{l}\text { Ludwig, Jens; University of Karlsruhe (TH), DFIU/IFARE } \\
\text { Treitz, Martin; University of Karlsruhe (TH), DFIU/IFARE } \\
\text { Rentz, O; University of Karlsruhe (TH), DFIU/IFARE; University of } \\
\text { Karlsruhe, Institute for Industrial Production } \\
\text { Geldermann, Jutta; University of Goettingen, Professorship for } \\
\text { Production and Logistics }\end{array}$ \\
\hline Keywords: & $\begin{array}{l}\text { AGGREGATE PLANNING, PRODUCTION PLANNING, CAPACITY } \\
\text { PLANNING, HEURISTICS }\end{array}$ \\
\hline Keywords (user): & Pinch Analysis, Seasonal production \\
\hline \multicolumn{2}{|l}{} \\
\hline
\end{tabular}

\section{ScholarONE" \\ Manuscript Central}


Production planning by pinch analysis for biomass use in dynamic and seasonal markets 
Production planning by pinch analysis for biomass use in dynamic and seasonal markets

Jens Ludwig*1a ${ }^{\text {1a }}$ Martin Treitz ${ }^{\mathrm{a}}$, Otto Rentz ${ }^{\mathrm{a}}$, Jutta Geldermann ${ }^{\mathrm{b}}$

${ }^{a}$ French-German Institute for Environmental Research (DFIU/IFARE), University of Karlsruhe (TH), Germany; ${ }^{b}$ Professorship for Production and Logistics, University of Goettingen, Germany

\footnotetext{
$1 *$ Corresponding author. Email: jens.ludwig@wiwi.uni-karlsruhe.de
} 


\begin{abstract}
The planning of production capacity has been extensively discussed in literature. Seasonal demand of products or seasonal availability of input materials can make the problem even more challenging, due to a constant need for capacity adjustments. For example, the energetic or industrial use of biomass has several distinct characteristics in contrast to conventional chemical processes, like a time dependent availability of raw materials. Therefore, suitable planning tools are required that take into account the dynamics of the production system (for example by following the seasons and the yearly changes). Thus a recently proposed heuristic approach for aggregate production planning when facing a seasonal demand is analyzed. This method is inspired by the graphical pinch analysis from chemical engineering; it is first illustrated with data from a bicycle company facing seasonal demand showing its plainness and some limitations. Then the transfer to situations with seasonal supplies of input materials is presented, as for biomass use in dynamic and seasonal markets. Using these applications, the uncomplex heuristic, its limits and its benefits are put up for discussion.
\end{abstract}

\title{
Keywords:
}

pinch analysis, aggregate production planning, capacity, seasonal market, biomass.

\section{Introduction}

The problem of planning the future production capacity of a company can be addressed in many ways, numerous standard methods exist in this wide field of scientific research (Luss 1982; Van Mieghem 2003; Mula et al. 2006 and Wu et al. 2005). When companies face a seasonal demand of products or a seasonal availability of input materials, the problem of short-term capacity adaptation can become especially challenging, as there may be a constant need to adapt the production rate. This aspect is for example relevant for the use of agricultural or forestal biomass with a seasonal availability for energy or fuel production. Consequently, the consideration of renewable energy sources with their special characteristics requires suitable planning tools that take into account the dynamics of the production system, for example by following the seasons and the yearly changes. Forecasting such seasonal demands is possible using various statistical methods, mostly aiming at identifying a seasonal component in historical demand data (see for example Winters 1960). The resulting prediction of a seasonally varying demand hast then to be translated into an operative production planning, that may employ inventory build-up, adjust the production rate, use overtime or outsourcing etc. to deal with seasonality and utilize capacity effectively. This task is generally referred to as aggregate production planning, research about formal solution approaches in this area already started in the 1950's (Holt et al. 1955). Since then the search for a compromise between the two extremes, levelling production by inventory holding and chasing demand has been a popular research topic and is still continuing. An overview of the formal approaches developed in this field is given in the works of (Buffa 1967; Nam and Logendran 1991; Pan and Kleiner 1994), the presented approaches include linear decision 
rules derived from calculus (Holt et al. 1955), production switching rules (Elmaleh and Eilon 1974), simulation (Jones 1967), as well as various kinds of mathematical programming and heuristics. In contrast to these more formal approaches, predefined production strategies are discussed in the following as a straightforward alternative to cost-based individual case optimizations. Depending on the magnitude of different decision-relevant costs, a strategy that offers a compromise solution between large inventories and numerous changes of the production rate may be beneficial. (Singhvi and Shenoy 2002; Singhvi et al. 2004) propose a graphical method that represents demand and supply data as composite curves and derives inspiration from pinch analysis. Pinch analysis is a classical method from the chemical process industry that aims at optimizing a system's performance by analyzing the process streams, i.e. mass and energy flows, and savings potentials through possible interconnections. A graphical illustration and planning heuristic derived from this methodology can be applied to product streams and the time-material production relationship. This is first explained using data from a bicycle company facing seasonal demand throughout the year. For this industrial case study, different straightforward production planning strategies are compared based on cost criteria. Limitations in the applicability of the method, as well as an extension using multiple pinch points are discussed. With certain adaptations, the graphical aggregate planning approach can be used for production planning when the supply of input materials is subject to seasonal changes, as is the case for biomass processing. The aim of this paper is to present a recently proposed unconventional approach for aggregate production planning and investigate its applicability for situations of seasonal demand and those of seasonal supply of input materials, its benefits and limitations. This paper stems from the authors contribution to the $19^{\text {th }}$ International Conference on Production Research 2007.

\section{Production planning with the pinch analysis approach}

Much attention has been focused on inventory control problems by logisticians and operations researchers. Given a producer's sales forecasts as a function of time, the initial inventory, the capacity restrictions and production costs, the question for planning arises: How should the production be scheduled in order to minimize the costs involved in production and storage adequate to fulfil the demand (Schneider 1938)? The answer, the determination of inventory, production and workforce levels over a planning horizon of typically one year is the subject of aggregate production planning theory. Although numerous OR models have been developed over the last decades, their practical applicability is often limited to specific cases with full knowledge of parameters and also by their rather formal nature. Therefore, operable approaches are needed, especially in light of increasingly fluctuating markets for end user products, but also for natural input materials used in industrial production. Similar assignment problems occur in chemical engineering, as in the optimization of heat exchanger networks. Here, the pinch analysis has been developed, which is outlined in the following paragraph. Its systematic can be partly transferred to production planning facing seasonal demand, as illustrated in the remainder of this section. The original approach presented by (Singhvi and Shenoy 2002; Singhvi et al. 2004) can be enhanced and expanded to production planning facing seasonal supply, as is explained in this contribution.

\subsection{The classical pinch analysis for heat integration}

The purpose of the thermal pinch analysis is to identify an optimal combination of hot process streams (that need cooling) and cold process streams (that have to be heated up) in a heat exchanger network. It is a systematic approach for minimizing losses of thermal energy by 
coming as close as possible to a reversible system (see Linnhoff et al. 1979; Geldermann et al. 2006a)). In order to achieve this, the thermal pinch analysis evolved from the graphical combination of hot and cold process streams to hot and cold composite curves in a temperature (qualitative parameter)-enthalpy (quantitative parameter) diagram as shown in Figure 1, The potential for heat reuse can then be read off from the diagram or calculated in an optimization derived from the classical transport algorithm from operations research (see Cerda et al. 1983). In its first step the pinch analysis yields the best possible heat recovery at the thermodynamic optimum. A trade-off between the savings in operating costs for the hot utility and the investment in the heat exchanger can also be considered in a more detailed analysis. The result of the pinch analysis is the energy savings potential for the considered set of processes.

\section{***** Figure 1 about here $* * * * * *$}

A similar approach is possible for minimizing water and wastewater use. In this case, the graphical approach is based on mapping the streams using the concentration of a contaminant as a qualitative parameter and the mass load as the quantitative one (Wang and Smith 1994). One part of this water pinch approach is a graphical matching of a supply line to a given demand composite curve similar to the following transfer to aggregate planning. Thus the use of a graphical adaptation of composite curves in order to match supply and demand under technical restrictions is at the centre of pinch analysis. The two mentioned basic applications for pinch analysis and several derived approaches are widely used in chemical engineering for identifying optimal process layouts. The time-dependency of available thermal energy is relevant when batch processes are investigated instead of continuous ones, it is dealt with in a further method in the field of pinch analysis called time pinch analysis (Wang and Smith 1995). Several aspects of these technical approaches can be transferred to alike structured economic problems, for example to target setting for investment planning (Zhelev 2005), to energy sector planning (Tan and Foo 2007), to scheduling of batch reactors (Foo et al. 2007) and to production planning (Singhvi and Shenoy 2002; Singhvi et al. 2004), which is the subject of the following sections.

\subsection{Translation of ideas from pinch analysis to production planning for seasonal demand}

In the following, some aspects of the pinch methodology are transferred to the area of aggregate production planning. Whereas the classical pinch analyses strives for near optimal solutions, the following transfer rather offers a heuristic strategy aiming at providing a sound production strategy under certain conditions. The time-material production relationship is used in the following for a pinch analysis inspired approach for aggregate production planning (Singhvi and Shenoy 2002; Singhvi et al. 2004), a similar representation of the aggregate planning situation was already used by (Buffa 1967). In this context, aggregate production planning is defined as the identification of a monthly overall level of production and inventory for an individual company facing fluctuating exogenous product demand. The focus of the analysis is the evaluation of seasonal changes on the demand or supply side and their consequences for setting the monthly level of production during the whole period considered. The central issue in this case is how to choose and adapt the production rate during the period in order to avoid stock-outs, minimize inventory and capacity changes and excess capacity. Based on material balances, a time versus cumulative material quantity plot can be derived in translation of the composite curves employed in original pinch analysis. The cumulative demand for each month is the only given value in this graphic, the cumulative production curve is a result of the verbally described production strategy and the inventory per month results from the sum of last month's inventory and the current month's production minus the 
current month's demand. Figure 2 shows different strategies for adapting the production level to a seasonally changing demand, which are described in the following. The transfer to production planning facing a seasonal supply of input goods is described after a more detailed look on different production strategies.
Deleted: Figure 2

Formatted: Font: $12 \mathrm{pt}$, Not Bold

Formatted: Font: 12 pt, Not Bold, Check spelling and grammar

$* * * * * \quad$ Figure 2 about here $* * * * * *$

The vertical axis represents the time of production as the quality parameter in analogy to the temperature level $\mathrm{T}$ in the thermal pinch analysis. The horizontal axis represents the cumulative demand and production respectively of units to a certain time, which is the quantity parameter in analogy to the enthalpy $\Delta \mathrm{H}$, describing the sum of internal energy of a thermodynamic system. One demand composite curve is given, for example by forecasts and

| one "reasonable" production composite curve has to be defined (cf. Figure 2). The right diagram shows the cumulative monthly balance of demand and units produced with the chosen production strategy, i.e., the inventory or stock-out for each month (the smallest sub period chosen here). Several production strategies are shown in Figure 2 they are used in the following for motivating and deriving the production planning strategy inspired by pinch analysis that aims at a compromise between level and chase strategies. This pinch-inspired strategy is expressed by a straight line starting from the given initial inventory and being tangent to the given demand composite curve. A change of the production rate in the tangent point is chosen in a way that this second part of the production composite curve passes through the desired ending inventory in the last period. This informal aggregate planning technique (obviously not guaranteeing an optimal result) is an extension of simple decision rules still prevalent in practice (Buxey 1995). The motivation for each of the straightforward production strategies as well as characteristics and extensions of the pinch-inspired strategy are discussed in the following.

\subsection{Discussion of production strategies}

For adapting the level of production to a seasonal demand, different strategies can be discussed based on their consequences on underlying decision-relevant cost factors. The term "strategy" is used here as a description of how to set the production rate for each month of the whole regarded forecasting horizon, forgoing any calculation steps. While investment dependent costs, labour costs and material costs are not in the focus of aggregate planning decisions, other costs related to inventory, stock-out penalties and capacity adjustments (like hiring and layoff) determine the suitability of "level", "chase" and compromise strategies. Subcontracting or overtime are not regarded in this abstraction, they could of course be integrated in the regarded strategies if they are applicable options for a company. The strategies regarded here illustrate different ways based on flexibility and costs to comply with | the demand composite curve and to supply the required aggregated demand (cf. Table 1). Besides the two pinch-inspired production strategies described in the following, they are rather obvious benchmark strategies following the shape of the cumulated demand curve in different ways, causing different refitting and inventory costs. Their choice can be based on a rough calculation of decision relevant cost if data is known, or alternatively on general but not exactly numeralized production process characteristics.

Variable Production Level with one Pinch Point is the already mentioned strategy derived from pinch analysis by (Singhvi and Shenoy 2002; Singhvi et al. 2004). Whereas they find this strategy to deliver the same results as a standard linear optimization based on cost assumptions for a specific example, the focus of this paper is its comparison with alternative production strategies concerning applicability and the quality of the results. This strategy

Formatted: Font: $11 \mathrm{pt}$, Not Bold

Formatted: Font: $11 \mathrm{pt}$, Not Bold, Check spelling and grammar

Deleted: Table 1
Formatted: Font: 12 pt, Not Bold

Formatted: Font: 12 pt, Not Bold Check spelling and grammar

Deleted: Figure 2

Formatted: Font: $12 \mathrm{pt}$, Not Bold, Check spelling and grammar

Deleted: Figure 2

Formatted: Font: 12 pt, Not Bold 
consists of choosing the minimal production rate from the starting point (origin or given initial inventory) that does not create stock-outs, i.e., rotate a straight line around the starting point until it touches the cumulative demand curve. The point where this line is tangent to the demand composite curve is called pinch point and the production rate is adapted here in a break with its second part ending in the point required by the demand composite curve. Thus the aim of this strategy is to identify, with stock-outs being prohibited, the production rates for the high and low season and the point in time, when the production rate is changed.

Furthermore, inventory accumulated before is completely depleted at this point, as can also be read off the grand composite curve (right part of Figure 2), which means that possible production bottlenecks due to uncertainties are most likely in this month.

However, this strategy generates stock-outs for some demand patterns, especially if monthly demand fluctuation is high or no ending inventory is planned. In case such stock-outs occur, we propose two corrective strategies: Firstly, the higher production rate before the pinch point could be maintained for as many periods, as are needed in order to build up sufficient inventory levels. This solution is easy to implement in a software tool, but reduces the graphical simplicity, its economic effect is to increases inventory costs, but to pass on additional adjustments of the production rate.

\section{***** Table 1 about here $* * * * * *$}

A second solution to eliminate the problem of stock-outs is the strategy called Variable Production Level with multiple Pinch Points, which includes a repeated adaptation of the production rate in each pinch point, determined as the point of contact of the minimal production rate below the demand composite curve, starting from the last pinch point. This strategy may obviously entail several adaptations of the production rate, however only in cases where the one pinch point strategy leads to stock-outs. As this strategy is viable for most given demand patterns, it was superior to the other strategies in most cases. This strategy could be further extended by considering the trade-off between stock-outs, inventory and capacity adaptations for every pinch point, however at the expense of its intuitive simplicity. The Average Production, Max-Zero and the Chase strategy are used as benchmarks for the evaluation of the trade-off of the penalty for stock-outs on the one hand and the inventory costs on the other. Furthermore, these most basic strategies are still prevalent in industry, which is discussed later. Depending on the exact cost factors of a company, one of these elementary strategies may certainly dominate the proposed variable production strategies. In any case, the graphical representation used still provides an intuitive overview to planners, who can read off the required capacity of the inventory and the production facility, represented by the reciprocals of the slopes of production composite curves' slopes. Challenging for the application of a pinch-inspired strategy is the determination of the starting time interval. In contrast to the thermal pinch analysis in which all heating and cooling requirements have to be sorted according to their quality parameter temperature and resulting a theoretical minimal utility target, the sorting of the demand in the production pinch analysis is infeasible. Consequently, the analysis can result in sub-optimal solutions, and the results significantly alter depending on the selected starting interval. Experiments with several data sets indicated that the method delivers most favourable results for a starting interval chosen as the beginning of the peak season. Thus this change from low to high season is proposed as the starting interval when applying this method. Of course, more comprehensive research concerning the influence of the chosen starting interval and in general of the shape of the demand on the results is necessary. 


\subsection{Case study with seasonal demand}

In the following the monthly production of a reference company producing bicycles in China is taken as an illustrative case study (cf. Geldermann et al. 2006b), which typically has a seasonal changing demand throughout the year (cf. Table 2). Five basic strategies for production planning are discussed (cf. Table 1) here. Since the seasonal increase of demand starts in October it is taken as the starting month of the evaluation.

\section{$* * * * *$ Table 2 about here $\quad * * * * * *$}

Table 2 shows the demand for each regarded month and the corresponding production rate according to the five applied strategies. The costs of each production strategy are calculated using observed and estimated values for material, labour, workforce changes and inventory. While (Singhvi and Shenoy 2002; Singhvi et al. 2004), use similar assumed costs for a linear optimization and compare the result to the pinch strategy, here the resulting costs of different strategies are compared.

The relevant costs for choosing the production strategy in this basic calculation are hiring and layoff costs on one hand and inventory and stock-out costs on the other hand. As the latter two costs favour frequent changes in the production rate (only determined by the workforce in this case) and the first two punish such changes of the production rate (equal to the production capacity in this case), the pinch-inspired setting of the production rate is used to find a compromise. In this specific example, the strategies inspired by pinch analysis result in lowest costs, meaning they offer the best compromise between the objectives of low inventory/stockout and a small number of costly capacity adaptations. In general, optimality of results is obviously not guaranteed. The aim of the method is rather to deliver either a good starting solution for further investigations or a simple guideline for identifying solutions that are superior to other straightforward production strategies. However, as stated before, the determination of the starting time interval of the evaluation highly influences the results of the analysis, which makes necessary more detailed research about the applicability to arbitrary demand lines.

\section{Transfer to production planning with seasonal supply}

Besides the application to aggregate planning facing seasonal demand, this heuristic can be applied to adapt the production rate and from this the needed overall capacity to a seasonally varying input material. The use of biomass as an input material for energy or fuel production could be regarded here as in contrast to conventional chemical processes, it has several distinct characteristics: Raw materials differ in quality, have a time dependent availability, come from decentralized sources and require adjusted logistics operations. For example the conversion of residual forestal wood or unused biomass from field crop to high quality combustibles (pellets, biogas or even synthetic fuel) is becoming an ample field of research. Consequently, the consideration of renewable energy sources with their special characteristics requires suitable planning tools that allow to plan ahead if demand suffers seasonal swings. The increasing use of biomass for industrial processes like power or fuel generation often limits the availability of inexpensive input materials for large scale processing. The storage costs for ensuring a steady supply of certain seasonally available input materials can become prohibitive for certain uses, especially due to many natural materials' poor transportability (low energy content) and its tendency to decay. On the other hand, excess capacity has to be minimized when following the seasons and the yearly changes, limiting the applicability of a pure chase strategy. Summarizing, the planning problem can be similar to finding the optimal production rate in aggregate planning facing seasonal demand. Thus, we propose the use of 
the production pinch analysis as a straightforward approach for production planning facing seasonally varying input factors. The graphical production pinch approach is used in this case for adapting the processing rate to the supply of a temporally available input material, e.g. biomass. Figure 3 shows how the graphical method presented before can be adapted to planning for seasonal supply: the processing curve is approached here to a given supply line from its upper side. In order to avoid input shortages, cumulated processing must not exceed the cumulated supply, thus the inversion of the two curves.

Formatted: Font: $12 \mathrm{pt}$, Not Bold

Formatted: Font: 12 pt, Not Bold, Check spelling and grammar

Deleted: Figure 3

\section{$* * * * * \quad$ Figure 3 about here $* * * * * *$}

In this case of seasonal supply, the aim of the method is to process all the available input material at minimal peak processing rates (i.e., with minimal excess capacity in the low season) and without shortages. Changes in the processing rate will result in certain costs in this case too, however probably to a rather small extent as most installations in this sector are highly automated. The maximum processing rate can be read off the graphic (reciprocal of the processing curves' slopes), allowing to determine the required overall capacity of the installation and thus investment related costs. Whereas a constant processing rate strategy is optimal with regard to capacity utilization, it will either not use the total seasonally available input material (fix processing rate) or lead to shortages (average processing rate) that may bring to a halt the whole process or require costly substitute materials. The Chase strategy minimizes storage-related costs, however at a high required maximum capacity, which is consequently poorly utilized when regarding the whole period. Applying a production strategy defined by one or multiple pinch points in analogy to the case of seasonal demand can result in a good compromise between different costs from storage of materials, capacity investment, possibly costs for adapting the processing rate, with downtimes due to shortages of input material being avoided. Again, the graphical planning scheme allows planners to quickly identify the estimated storage needed in every month as well as the possible bottleneck months when stocks are fully depleted or at least down to a chosen safety stock. Depending on the regarded technical processes and their cost characteristics, unambiguous preferences may render unnecessary such considerations of multiple factors, as for example the conversion of biomass to fuels may economically require a constant use of costly aggregates. As mentioned above, storage of some materials may also be limited to short phases due to the materials' tendency to decay. If this is the case and investment related costs are not dominant, the Max-Zero strategy will be preferred. However, more flexible aggregates as for example decentralized pre-treatment of biomass, e.g. pelletization of straw or biogas installations that can run of multiple input materials (see for example Koch et al. 2005) require a systematic analysis of ideal capacity and processing rates. As for the case of aggregate production planning for seasonal demand, the pinch-inspired heuristic is not claimed the most suited approach, but one of many possible solutions. For both cases, the suitability of the presented approach is discussed in the following.

\section{Discussion: Simple heuristics versus standard planning approaches}

Compared to standard operations research methods like linear optimization based on a mathematical model of the total costs, production planning using pinch analysis is a highly aggregated approach, for rather simple problems. The applicability of this basic graphical heuristic is limited to suited demand patterns, and the optimality of results is not guaranteed. As the production pinch approach does not regard the magnitude of different costs, it may be regarded rather as a simple strategy for finding quick solutions or a starting solution that reduces complexity for further more formal analyses. 
However, the application of the pinch analysis methodology to production planning provides a simple but effective tool for analyzing production strategies of a company facing seasonal demand or supply. This heuristic requires no detailed analysis of single cost factors and can therefore support the understanding and planning of production levels facing seasonal demand or supply. Thus, an easy to use implementation of the method possibly allowing for including forecasting methods and multi-period planning for considering dynamic growth could be a valuable approach especially for small enterprises that generally do not use mathematical methods for production planning. In a survey-based research, (Buxey 1995) found that aggregate production planning is never undertaken in industry in the way promoted by literature. Instead he identified a prevalence of simple decision rules for coping with seasonal demand, mainly mere chase strategies. For these cases, the pinch-inspired heuristics seem beneficial, as by acting as a simple filter for demand or supply peaks they can contribute to reduce changes in the production rate while showing the required storage capacity. The tendency of the regarded single pinch point and multiple pinch point strategies to smooth the production compared to given downstream demand or upstream supply can be seen as positive for multilevel supply chains, as seasonal fluctuations are prevented from building up along the supply chain. Intuitive graphical planning tools for rather independent units may also find higher acceptance of the users than more complex and daunting mathematical approaches, which may furthermore be limited by complex multi-level supply chain structures. The need for a quantification of planning objectives is another possible obstacle for a more formal planning approach. For instance, (Gilgeous 1988) argues that production planning has to satisfy multiple objectives and some, like the employee's reluctance towards sharp changes in the size of the workforce cannot be directly quantified. For any aggregate planning approach, the underlying view of the production rate to be freely changeable and thus employees to be removable as needed by the company is certainly a critical point. While such a view was found in the company of the case study, the presented method is rather flexible when implemented in a small software tool and allows for more social views. Additional constraints can be included in this and other planning approaches for a more realistic view, as well as higher costs for laid-off workers, etc. Ideally, several approaches could be included in a decision support system allowing a comparison of results and, if other approaches are preferred at least to use the intuitive representation of planning results in the form of cumulative composite curves and the resulting monthly inventory. The idea to transfer concepts of engineering and physics to economy seems promising, especially for pinch analysis the diverse application areas (c.f. section 2.1) are striking.

\section{Conclusions}

The application of the pinch analysis methodology to production planning provides a simple but effective tool for analyzing production strategies when monthly sales exhibit predictable seasonal highs and lows. Based on cost structures, different production strategies can be evaluated; those based on pinch analysis often provide a good compromise between inventory costs and capacity adaptation costs and capacity investment respectively. The basic pinch analysis inspired concept for dealing with a seasonal demand by (Singhvi and Shenoy 2002; Singhvi et al. 2004) can be improved by an opening step comprising the choice of a beginning period with the highest demands. Moreover, different strategies have been introduced. The idea to select a strategy with multiple pinch points was proposed in order to overcome stockouts possible in the one pinch point strategy. Especially this strategy seems to be promising due to its larger applicability. Further investigations are necessary as regards the shape of the demand curves suited for the application of this method. The concept of graphically analyzing the planning situation for identifying suited heuristics as those inspired by pinch analysis is 
further transferred to planning the use or treatment of seasonally accruing material flows as for example forestal biomass. Whereas this graphical heuristic based on the pinch analysis seems promising for a basic planning of processing capacity and storage, the applicability and limitations have to be investigated in more detail. For specific cases, process data may show that either overall capacity or storage cost is a dominant criterion and no compromise solution is required. However, an increased competition for raw materials in the future due to new paths for biomass utilization may increase the relevance of availability of input materials and thus the need for foresighted planning of seasonal production. While the presented method cannot compete with other formal aggregate planning approaches in terms of universal applicability or promised optimality of the result, it may serve as a contribution for bridging the gap between sophisticated but seldom applied scientific solutions and managerial rules of thumb.

\section{References}

Buffa, E.S. 1967. Aggregate Planning for Production - Three Approaches, Efficient and Easy to Apply. Business Horizons, Fall 1967, 87-97

Buxey, G. 1995. A managerial perspective on aggregate planning. International Journal of Production Economics, 41 127-133

Cerda, J. et al. 1983. Minimum utility usage in heat exchanger network synthesis - A transportation problem. Chemical Engineering Science, 38 (3) 373-387.

Elmaleh, J. and Eilon, S. 1974. A new approach to production smoothing. International Journal of Production Research, 12 (6), 673-681.

Foo, D.C.Y. et al. 2007. Pinch Analysis Approach to Short-Term Scheduling of Batch Reactors in Multi-Purpose Plants. International Journal of Chemical Reactor Engineering, 5 (A94).

Geldermann, J. et al. 2006a. Integrated technique assessment based on the pinch analysis approach for the design of production networks. European Journal of Operational Research, 171 (3) 1020-1032.

Geldermann, J. et al. 2006b. Integrated Process Design for the Inter-Company Plant Layout Planning of Dynamic Mass Flow Networks Karlsruhe, Universitätsverlag Karlsruhe.

Gilgeous, V. 1988. A Functional Objective Search Approach to Aggregate Planning. International Journal of Operations \& Production Management, 8 (1), 48-62.

Holt, C. et al. 1995. A Linear Decision Rule for Production and Employment Scheduling. Management Science, 2 (1), 1-30.

Jones, C.H. 1967. Parametric production planning. Management Science, 13 (11), 843-866. 
Koch, M. et al. 2005, "Techno-economic evaluation of biomass digestion techniques and their optimised siting," In Current development of Green IPPs: experiences, challenges, and strategies. Workshop of the EC-ASEAN Green Independent Power Producers Network, O. Rentz et al., eds., Karlsruhe, 11-20

Linnhoff, B. et al. 1979. Understanding heat exchanger networks. Computers and Chemical Engineering, 3, 295-302.

Luss, H. 1982. Operations Research and Capacity Expansion Problems: A Survey. Operations Research, 30 (5) 907-947.

Mula, J. et al. 2006. Models for production planning under uncertainty: A review. International Journal of Production Economics, 103, 271-285

Nam, S-J. and Logendran, R. 1991. Aggregate production planning - A survey of models and methodologies. European Journal of Operations Research, 61, 255-272.

Pan, L. and Kleiner, B.H. 1994. Aggregate planning today. International Journal of Materials \&Pproduct Technology, 9 (4-6), 516-523.

Schneider, E. 1938. Absatz, Produktion und Lagerhaltung bei einfacher Produktion. Archiv für mathematische Wirtschafts- und Sozialforschung, 4, 99-120.

Singhvi, A. et al. 2004. Pinch analysis for aggregate production planning in supply chains. Computers and Chemical Engineering, 28, 993-999.

Singhvi, A. and Shenoy, U.V. 2002. Aggregate Planning in Supply Chains by Pinch Analysis. Transaction of the Institution of Chemical Engineers, 80 (A), 597-605.

Tan, R. and Foo, D. 2007. Pinch analysis approach to carbon-constrained energy sector planning. Energy, 32, 1422-1429.

Van Mieghem, J. 2003. Capacity Management, Investment, and Hedging: Review and Recent Developments. Manufacturing \& Service Operations Management, 5 (4) 269-302.

Wang, Y.P. and Smith, R. 1994. Wastewater Minimisation. Chemical Engineering Science, 49 (7) 981-1006.

Wang, Y.P. and Smith, R. 1995. Time Pinch Analysis. Transaction of the Institution of Chemical Engineers, 73A, 905-914.

Winters, P. 1960. Forecasting Sales by Exponentially Weighted Moving Averages. Management Science, 6 (3) 324-342.

Wu, S. et al. 2005. Managing Capacity in the High-Tech Industry: A Review of Literature. Engineering Economist, 50 (2) 125-158.

Zhelev, T.K. 2005. On the integrated management of industrial resources incorporating finances. Journal of Cleaner Production, 13, 469-474. 


\section{Tables}

Table 1: Regarded production strategies

\begin{tabular}{|l|c|c|c|}
\hline \multicolumn{1}{|c|}{ Strategy } & $\begin{array}{c}\text { Pinch } \\
\text { Points }\end{array}$ & $\begin{array}{c}\text { Capacity } \\
\text { Adjustments }\end{array}$ & $\begin{array}{c}\text { Stock-Outs } \\
\text { allowed }\end{array}$ \\
\hline $\begin{array}{l}\text { Fixed Production Level } \\
\text { with one Pinch Point }\end{array}$ & 1 & 0 & no \\
\hline $\begin{array}{l}\text { Variable Production Level } \\
\text { with one Pinch Point }\end{array}$ & 1 & 1 & no \\
\hline $\begin{array}{l}\text { Variable Production Level } \\
\text { with multiple Pinch Points }\end{array}$ & var. & var. & no \\
\hline Average Production Level & 0 & 0 & yes \\
\hline Max-Zero Strategy & 0 & 1 & no \\
\hline Chase Strategy & var. & var. & no \\
\hline
\end{tabular}


Table 2 : Comparison of production strategies for the case study with seasonal demand

\begin{tabular}{|c|c|c|c|c|c|c|c|}
\hline & & $\begin{array}{c}\text { Fixed Production } \\
\text { with one Pinch } \\
\text { Point }\end{array}$ & $\begin{array}{c}\text { Variable } \\
\text { Production with } \\
\text { one Pinch Point }\end{array}$ & $\begin{array}{c}\text { Variable } \\
\text { Production } \\
\text { multiple Pinch } \\
\text { Points }\end{array}$ & $\begin{array}{l}\text { Average } \\
\text { Production } \\
\text { Level }\end{array}$ & $\begin{array}{l}\text { Max-Zero } \\
\text { Strategy }\end{array}$ & Chase Strategy \\
\hline \multicolumn{2}{|c|}{$\begin{array}{r}\text { Production Rates } \\
\text { [\#/ Month] }\end{array}$} & T[Monthe & $\hat{f}^{\text {Time }}$ [Months] & fimonims & $\begin{array}{c}\text { Time } \\
\text { [Months] }\end{array}$ & Time $_{\text {[Months] }}$ & fimonthe \\
\hline \multicolumn{8}{|l|}{ Demand } \\
\hline October & 90.000 & \multirow{12}{*}{108.000} & \multirow[t]{7}{*}{108.000} & \multirow[t]{5}{*}{108.000} & \multirow{12}{*}{83.333} & \multirow{6}{*}{166.667} & 90.000 \\
\hline November & 90.000 & & & & & & 90.000 \\
\hline December & 110.000 & & & & & & 110.000 \\
\hline January & 130.000 & & & & & & 130.000 \\
\hline February & 120.000 & & & & & & 120.000 \\
\hline March & 90.000 & & & 90.000 & & & 90.000 \\
\hline April & 80.000 & & & 80.000 & & \multirow{6}{*}{0} & 80.000 \\
\hline May & 60.000 & & \multirow{5}{*}{48.800} & 60.000 & & & 60.000 \\
\hline June & 50.000 & & & 50.000 & & & 50.000 \\
\hline July & 50.000 & & & 50.000 & & & 50.000 \\
\hline August & 60.000 & & & 60.000 & & & 60.000 \\
\hline September & 70.000 & & & 70.000 & & & 70.000 \\
\hline \multicolumn{2}{|c|}{ Annual Cost $[\mathrm{k} \epsilon]$} & 30.918 & 22.539 & 21.702 & 23.465 & 37.892 & 22.816 \\
\hline \multicolumn{2}{|c|}{ Final Inventory [\#] } & 296.000 & 0 & 0 & 0 & 0 & 0 \\
\hline
\end{tabular}




\section{Figure Captions}

Figure $1:$ Thermal pinch analysis

Figure 2 : Production planning for seasonal demand by pinch analysis (adapted from Singhvi and Shenoy 2002)

Figure 3 : Production planning for seasonal supply by pinch analysis

5740 Words

http://mc.manuscriptcentral.com/tprs Email: ijpr@lboro.ac.uk 


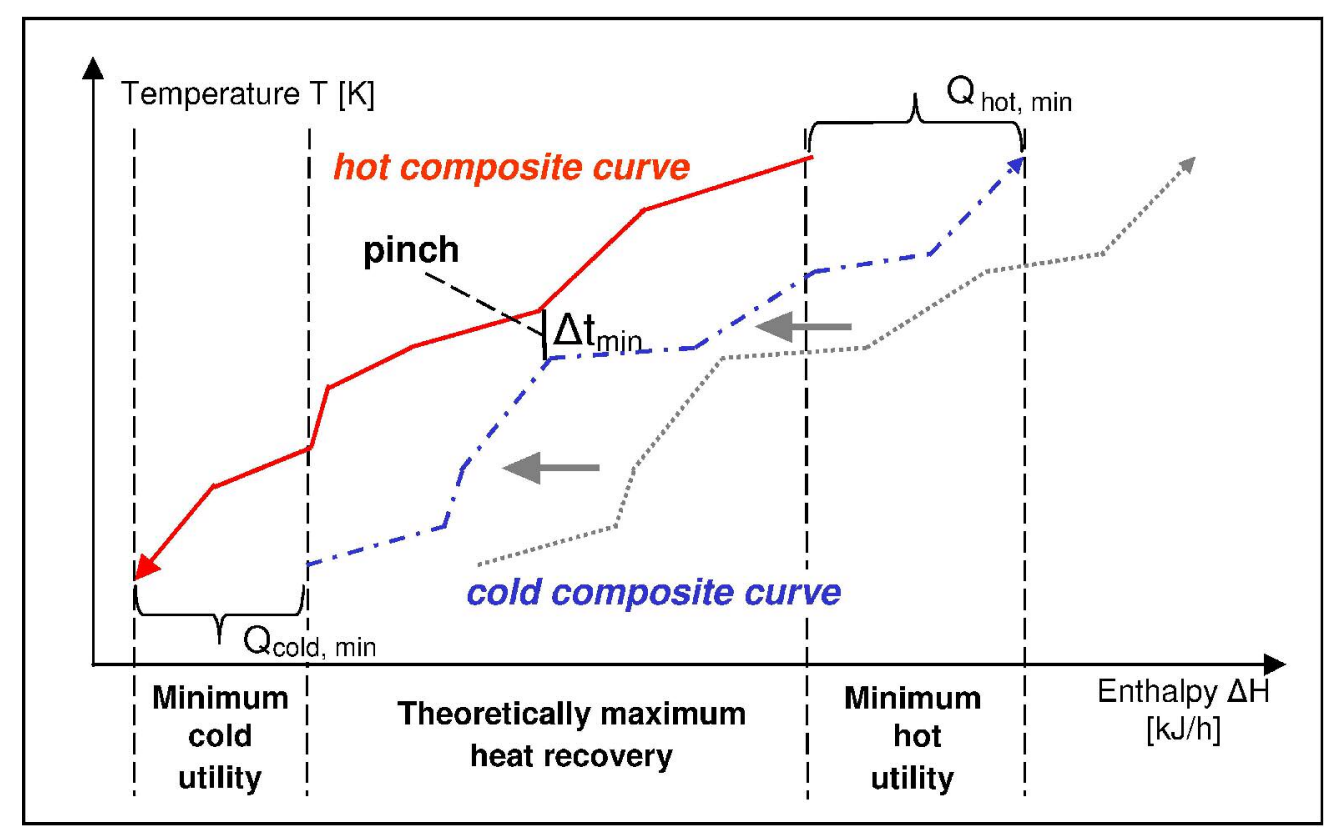

Thermal pinch analysis $175 \times 109 \mathrm{~mm}(600 \times 600 \mathrm{DPI})$ 


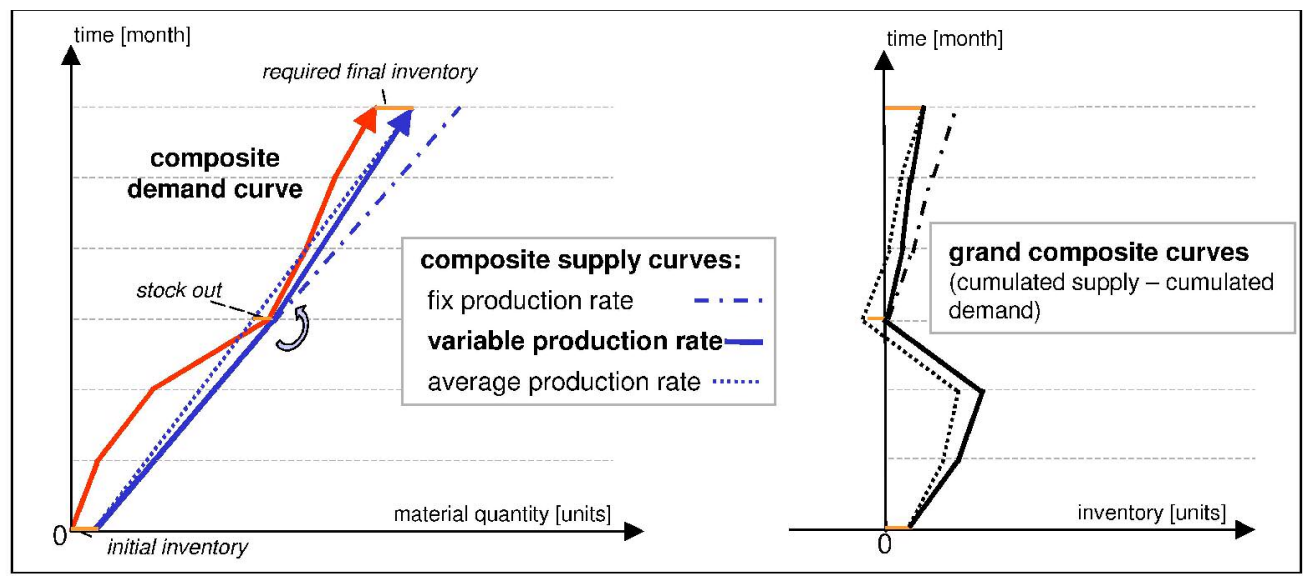

Production planning for seasonal demand by pinch analysis (adapted from (Singhvi and Shenoy 2002))

$194 \times 84 \mathrm{~mm}(600 \times 600$ DPI $)$ 


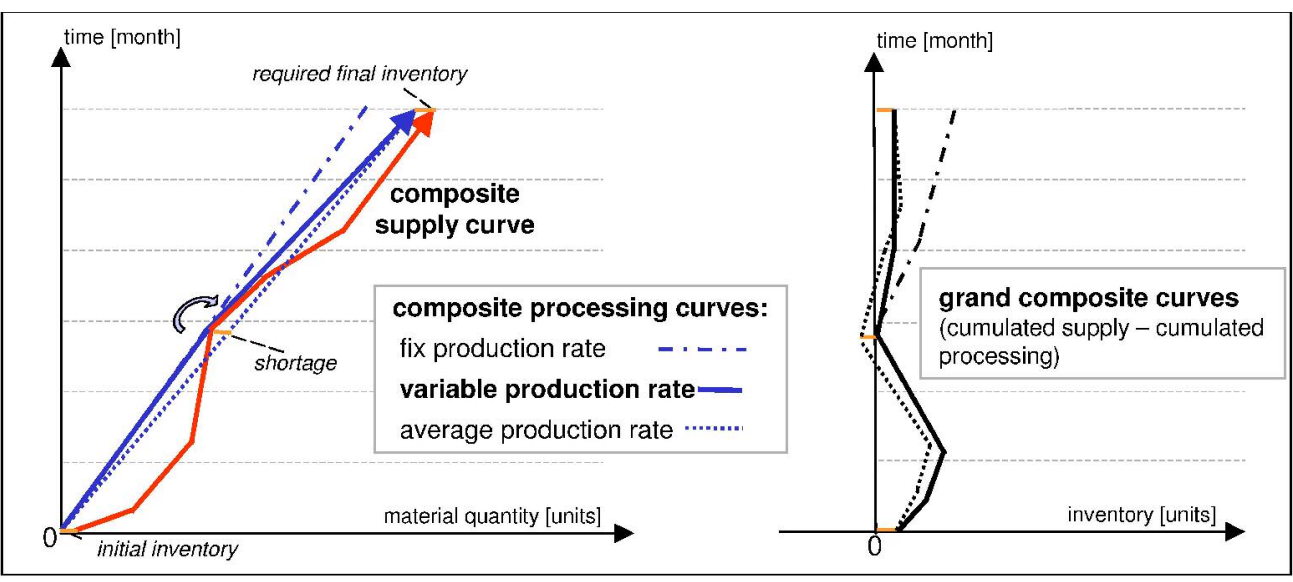

Production planning for seasonal supply by pinch analysis $194 \times 84 \mathrm{~mm}(600 \times 600 \mathrm{DPI})$ 